\title{
Electro-homeopathy: select numerical aspects
}

Keywords: homeopathy, natural medicines, alternative medicines, pathophysiological, surgeons

\section{Introduction}

Chinese natural medicines are mostly made using part of the spagyric method. They dominate the global market. So much that main-land Europe's and even Italian native natural medicines have almost become untraceable (Roman Republic onwards we note natural medicines was the main stay). Natural \& Alternative medicines are now being focused upon more as source for new drug discovery. ${ }^{1,2}$

Natural; Ayurveda; Chinese; homeo; electro homeo; unani; etc., medicines are considered as 'alternative medicines'. Allopathy is called as 'conventional medicine'. It has two branches namely (i) internal (ii) invasive medicine. Allopathic internal medicine arose from phyto-herbals. About the genetics of invasive medicine in England Margaret Pelling ${ }^{3}$ the medical historian Oxford University in very many words indicate that between c.1500-1700 the barbers were the surgeons of Europe ${ }^{4}$ known; formed company and guilds known as Company of Barber Surgeon and Surgeon Barber associations, respectively.

However, our study shows that Europe was actively using herbs (as internal medicine) and more importing know-how from across the continents as her blue water trading ships could provide e.g., Chincona for fever/malaria; turmeric \& spices from India (collateral info). We further find that in the fast industrializing environment a century later Christian Friedrich Samuel Hahnemann (c.1755-1843) gave to Europe and the world the Homeopathic school of medicine. It was chemistry based and was administered on the clinical concept of "like-cures-like" - in other words use toxins to cure toxin inflicted malady $\backslash$ pathology. It worked on the therapeutic principle of low dilution $=$ higher efficacy.

Either has since been proven as grossly erroneous for therapeutic purposes. Does not withstand numerical common sense and certainly not via in-vivo results. Count Cesare Mattei (c1809-1896) the celebrated Italian scientist invented 'spagyric' (alchemy in Greek/ Latin) for therapeutic purposes. ${ }^{5}$ It was phyto-extraction process alias natural medicine called as Electro-Homeopathy (EH). This method permitted up-regulated dosing as per clinical indications (pathophysiological requirements) extending into bolus. As against this, the famous German anatomist Rudolf Hoernale (c.1814-1918) has proven that the science of anatomy and invasive medicine was not known in Greece. That the Greek medicine experts use to visit India to learn. ${ }^{6}$ The Ayoorveda specialists practiced internal medicine ${ }^{7}$ surgery, had surgical implements \& principles of practices. ${ }^{8}$ Citing official/state sponsored paleographs date to c.925-35 A.D., Deepak Bhattacharya ${ }^{9}$ has proven that in Ancient India medicine specialists were known as 'vaidya' (doctor) and practitioners of invasive medicines were known as 'vesakas' (surgeons). Either being technical phones in Sanskrit lingua. In medieval India, in the central India kingdom of the Nizams alias Hyderabad state (c,1500-1900) an indoarabic modified school of natural internal medicine was practiced
Volume 2 Issue 2 - 2018

\author{
Susant Kumar Padhi,' Asad Kesari, ${ }^{2}$ Deepak \\ Bhattacharya ${ }^{3}$ \\ 'EH Medical College \& Lab, India \\ ${ }^{2}$ Electro Homeo Medical Centre, India \\ ${ }^{3}$ Fight Cancer at Home, India
}

Correspondence: Deepak Bhattacharya, Fight Cancer at Home, Bhubaneswar-751002, India, Tel 8895997259,

Email oddisilabl@dataone.in

Received: February 22, 2018 | Published: March 20, 2018

being fully state sponsored (supporting info). And most of such panglobal heritage has often been labeled as 'bogus hoax or as quackery'. During present time (catalyzed by the Vietnam war) the indo-china histo-cultural practice of munching/swallowing artemisia annua herbs (non flowering stage) to thwart pyrexialfever and or fail malaria has evolved as the 'Artisunate' intravenous injection alias ACTs - and being awarded the Nobel prize (2015).

Electro-homeopathy has a bulk drug making process. It is fully in sync with latest in modern sciences. Therefore, there is a case to look in and report back, specially about Electro-homeopathy which has remained virtually un-reported.

\section{Numerical aspects}

Therapeutics is based on fixed doses which in turn mean numerical modeling. However, the numerical aspects spagaryic method has not been discussed. We are working in such domain. In this brief communication we try to throw some light on few select aspects.

Electro homeopathy bulk drugs are made via the following steps.

a) Distillation

b) Fermentation

c) Incineration

a) Distillation yields oils (essential \& non essential amino acids) and flavinoids (aromas \& colour inflictors); all being liberated under thermo-dynamic stress). Are electrically negative. Distilled oils are poorly hygroscopic.

b) Contain no sugars; volatiles. These come in post fermentation.

c) Sugars \& volatiles are ion loaded, charge potentiated, known energy component of the drug. Minerals/trace elements come in post incineration (calcinations). They have ion and oil affinity and exhibit preferred mechanics. Result in reformation of neat-near pure compounds. 
The standard therapeutic unit in process spagyric is 'atomic mass unit' (AMU).

Now: 1 atom $=12$ Daltons $=12$ amu's (i.e., $1 \mathrm{amu}=1$ Dalton $=$ $1 / 12^{\text {th }}$ atom).

1 atom is chemically inert and is incapable of performing any chemical reaction. (However it can undergo collation via paramagnetism \& ion mediated pathways and result in up-regulation; critical threshold... etc.). EH takes this into account (vital).

The smallestlleast quanta for any chemical action are a molecule (therapeutics included). Specially, oily molecules are less reactive.

1 molecule $=12$ atoms $($ of distilled oil $)=(12 \times 12) 144$ amu's.

The mean sizelwt. of 1 atom being $1.660539040(20) \times 10^{-27} \mathrm{Kg}$. (being also the number for 12 amu's).

1 molecule of EH oil $=1.660539040(20) \times 10^{-27} \times 12$ amu's.

And, 1 droplet of distilled EH oil $=40,000$ molecules.

Which works out to $40,000 \times 12$ molecules and 40,000 $\times 12^{2}$ AMUs/ Daltons?

This is a large number is potent. Hence distilled oils are never used in raw form but admixed with expanders and or various types of carriers known as suspensions. EH does not use such concentrated oil as raw-direct (separate communication in press).

Therefore, EH is safe. Furthermore, 1 length dimension of a droplet (40,000molecules) of distilled (specially) essential Oil $=2 \mathrm{x}$ $10^{-9} \mathrm{~m}$. While the Vol of a molecule $=1.6 \times 10^{-10} \mathrm{~m}$ (Diameter $=10^{-10} \mathrm{~m}$; Thickness $\left.(\mathrm{h})=0.6 \times 10^{-10} \mathrm{~m}\right)$. Therefore the ratio of mass: amu is large (makes it easy handle at pharmacy $\backslash$ making stage and at pediatric clinical use stage).

\section{Discussion}

In modern pharmacology (conventional med) sterility and its quality $\operatorname{control}^{10}$ drug be the hall marks. Repeatabilty and predictability are another two most vital parameters of modern $\backslash$ conventional medicine. While safety be the jewel in the crown. Numerical aspects permits all this. Fold dilution results in potency down-regulation. All these features \& aspects are noted in the case of EH.

This communication (rapid-part communication) is limited to 'fermentation' as the works are ongoing. Spagyric process is historically native to Europe and whereas this alternative medicine school has a large body of practitioners in the Indian sub-continent. The objective herein is to throw some light on our study and about the fact that so that Occidental authorities may cast due diligence.

\section{Conclusion}

Electro Homeopathy is not homeopathy per-say. It is very different. It is scientific; numerically validable; forward looking; permits up-take and assimilation of most modern gadgetry; R \& D possible; employment enabling; primary health care oriented. It is potent and also mass formation enabled. Convenient form pharmacy perspectives i.e., permit easy making of EH in cottage industry (bulk drug even in parts/constituent wise).

\section{Acknowledgements}

We are thankful to the Organizers of All India EH Conference, Jan-2018, Cuttack, Odisa, To Dr. Pal (President); EH making plant in central Odisa; and others who all have assisted with the editing.

\section{Conflict of interest}

Author declares no conflict of interest.

\section{References}

1. Ameh SJ, Obiageri OO, Peace BC, et al. Medical herbalism and herbal clinical research: a global perspective. British Journal of Pharmaceutical Research. 2011;1(4):99-123.

2. Deepak Bhattacharya, BM Bhuyan, PK Pradhan, et al. Transmission Blocking of Year Round Resistant Malaria in Koraput (India) by OMARIA-A New Antimalarial Phytotherapy. British Journal of Pharmaceutical Research. 2013;3(1):54-77.

3. Amanda Smith. When barbers were surgeons and surgeons were barbers. The Body Sphere. 2015.

4. Barber surgeon. 2011.

5. Count Cesare Mattei. Photothèque Homéopathique. présentée par Homéopathe International; 1809-1896.

6. Rudolf Hoernale CIE. Studies in the Medicine of Ancient India Part-I. Osteology, of Bones of the Human Body. Oxford, Clarendon; $1907 ; 8: 252$.

7. Charak Samhita, Sarira Sthana Chapter V \& III X-Anatomy Section. Also enumerates the methodology of preparation of the human body before dissection.

8. Susruta, Sutra Sthana Chapter 7,8. (Vesaka/surgeon).

9. Select Palm Leaf Manuscripts on Health Care. Indian Journal of History of Science. 2014;49(3):294-297.

10. Deepak Bhattacharya, Sri Radha Krishna, Kedar Gouri Road, et al. A Discussion on Indian Indigenous Lal: Orlysate. International Research Journal of Pharmacy. 2012;3(8):176-182. 